\title{
Anabases
}

ANABASES Traditions et réceptions de l'Antiquité

$20 \mid 2014$

Varia

\section{Chronologie des traductions référencées}

\section{(2) OpenEdition}

1 Journals

Édition électronique

URL : http://journals.openedition.org/anabases/5094

DOI : 10.4000/anabases.5094

ISSN : 2256-9421

\section{Éditeur}

E.R.A.S.M.E.

\section{Édition imprimée}

Date de publication : 1 novembre 2014

Pagination : 287-290

ISSN : 1774-4296

\section{Référence électronique}

"Chronologie des traductions référencées », Anabases [En ligne], 20 | 2014, mis en ligne le 01

novembre 2017, consulté le 21 octobre 2019. URL : http://journals.openedition.org/anabases/5094

DOI : 10.4000/anabases.5094

\section{(c) Anabases}




\section{Chronologie des traductions référencées}

\begin{tabular}{|c|c|c|}
\hline Homère en hexamètres & Autres poètes, manifestes & Hors hexamètre \\
\hline \multirow[t]{4}{*}{$\begin{array}{l}1530 \text { Jean Mousset traduit } \\
\text { L'Iliade et L'Odyssée. La } \\
\text { traduction se perd. }\end{array}$} & $\begin{array}{l}1553 \text { Premiers poèmes mesu- } \\
\text { rés d'E. Jodelle }\end{array}$ & $\begin{array}{l}1539 \text { H. Salel, L'Iliade I-X } \\
\text { en décasyllabes }\end{array}$ \\
\hline & $\begin{array}{l}1573 \text { J. de la Taille, La } \\
\text { manière de faire des vers en } \\
\text { François, comme en Grec et en } \\
\text { Latin } \\
1574 \text { J.-A. Baif, Etrénes de } \\
\text { poézie fransoeze an vers mezu- } \\
\text { rés, comprenant Les Besognes } \\
\text { et les Jours }\end{array}$ & $\begin{array}{l}\text { 1574-80 A. Jamyn termine } \\
\text { L'Iliade de Salel en } \\
\text { alexandrins }\end{array}$ \\
\hline & & $\begin{array}{l}\text { 1603-14, G. Chapman, } \\
\text { L'lliade (vers de } 14 \text { syllabes } \\
\text { rimés) en anglais }\end{array}$ \\
\hline & & $\begin{array}{l}1711 \text { L'Iliade de Mme } \\
\text { Dacier (en prose) } \\
1716 \text { L'Odyssée }\end{array}$ \\
\hline $\begin{array}{l}1778 \mathrm{~J} \text {. Bodmer, L'Iliade et } \\
\text { L'Odyssée en allemand }\end{array}$ & $\begin{array}{l}\text { 1748-1773 Klopstock, } \\
\text { Messias, Oden }\end{array}$ & $\begin{array}{l}\text { 1715-20 L'Iliade d'A. } \\
\text { Pope, en pentamètres } \\
\text { iambiques }\end{array}$ \\
\hline $\begin{array}{l}1781 \text { J.-H. Voss, L'Odyssée et } \\
1793 \text { L'Iliade en allemand }\end{array}$ & & $\begin{array}{l}1767 \text { Ulyxea, Gonzalo } \\
\text { Perez, vers de } 11 \text { syllabes, } \\
\text { en espagnol }\end{array}$ \\
\hline
\end{tabular}




\begin{tabular}{|c|c|c|}
\hline & $\begin{array}{l}1796 \text { Goethe, Hermann und } \\
\text { Dorothea; } 1800 \text { (manuscrit), } \\
\text { Hölderlin, Der Archipelagus }\end{array}$ & \\
\hline $\begin{array}{l}1829 \mathrm{~N} \text {. Gneditch, L'Iliade } \\
\text { en russe }\end{array}$ & $\begin{array}{l}1821 \text { K. L. von Knebel, Von } \\
\text { der Natur der Dinge, Lukrez }\end{array}$ & $\begin{array}{l}\text { 1811-25 L'Iliade de } \\
\text { V. Monti (vers italiens de } \\
11 \text { syllabes) }\end{array}$ \\
\hline $\begin{array}{l}1849 \mathrm{~V} \text {. Joukovski, L’Odyssée } \\
\text { en russe }\end{array}$ & 1847 Longfellow, Evangeline & $\begin{array}{l}1850 \text { Leconte de Lisle } \\
\text { traduit L'Iliade en prose } \\
1861 \text { L'Odyssée }\end{array}$ \\
\hline $\begin{array}{l}\text { 1878-1916, en estonien, } \\
\text { J. Bergmann traduit la } \\
\text { Batrachomyomachie, l'Odyssée, } \\
\text { chants } 9,12,1-3\end{array}$ & $\begin{array}{l}1862 \text { A. Van Hasselt, Poèmes, } \\
\text { paraboles, odes et études } \\
\text { rythmiques }\end{array}$ & $\begin{array}{l}1874 \text { O. Mendes, L'Iliade } \\
\text { (décasyllabes), en portugais } \\
\text { du Brésil }\end{array}$ \\
\hline $\begin{array}{l}1900 \text { essais de traduction de } \\
\text { G. Pascoli }\end{array}$ & $\begin{array}{l}1877-89 \text { G. Carducci, Odi } \\
\text { barbare }\end{array}$ & \\
\hline $\begin{array}{l}\text { 1906-1912 G. Murnu, } \\
\text { L'Iliade, en aroumain }\end{array}$ & & \\
\hline \multirow[t]{2}{*}{$\begin{array}{l}1923 \text { M. Faggella, L'Iliade, en } \\
\text { italien } \\
1925 \text { du même, L'Odyssée }\end{array}$} & $\begin{array}{l}1925 \text { P. Servien, Essai sur les } \\
\text { rythmes toniques du Français }\end{array}$ & $\begin{array}{l}1924 \text { G. Murnu, L’Odyssée } \\
\text { (11 syllabes) } \\
1925 \text { V. Bérard, L'Odyssée } \\
\text { (prose hexasyllabique) }\end{array}$ \\
\hline & $\begin{array}{l}1930 \text { J. Tardieu traduit } \\
\text { L'Archipel de Hölderlin en } \\
\text { hexamètres libres }\end{array}$ & $\begin{array}{l}1927 \text { Obras completas de } \\
\text { Homero, por Luis Segalá y } \\
\text { Estalella (prose) }\end{array}$ \\
\hline $\begin{array}{l}1938 \text { A. Öpik, L'Odyssée 1-12 } \\
\text { en estonien }\end{array}$ & $\begin{array}{l}1938 \text { C. A. Nunes, Os } \\
\text { Brasileidas, épopée brésilienne } \\
\text { en hexamètres }\end{array}$ & $\begin{array}{l}1937 \text { P. Mazon, L'Iliade } \\
\text { en prose, la traduction des } \\
\text { Belles Lettres }\end{array}$ \\
\hline \multicolumn{3}{|l|}{$\begin{array}{l}1945 \text { C. A. Nunes, L'Iliade en } \\
\text { portugais du Brésil } \\
1945 \text { V. Veresaev, en russe, } \\
\text { L'Odyssée, } 1949 \text { L'Iliade }\end{array}$} \\
\hline $\begin{array}{l}1951 \text { R. Lattimore, L'Iliade, } \\
\text { en anglais, en hexamètres } \\
\text { libres }\end{array}$ & & $\begin{array}{l}1955 \text { Ph. Jaccottet, } \\
\text { L'Odyssée (vers libre de 10, } \\
\text { 12, 14, } 16 \text { syllabes) }\end{array}$ \\
\hline $\begin{array}{l}1960 \text { A. Annist, L'Iliade en } \\
\text { estonien }\end{array}$ & & $\begin{array}{l}1955 \text { Homère dans la } \\
\text { Pléiade, R. Flacelière } \\
\text { et V. Bérard, prose } \\
\text { hexasyllabique }\end{array}$ \\
\hline $\begin{array}{l}1962 \text { C. A. Nunes, L’Odyssée } \\
\text { en portugais du Brésil } \\
1963 \text { A. Annist, L'Odyssée en } \\
\text { estonien }\end{array}$ & & \\
\hline
\end{tabular}




\begin{tabular}{|c|c|c|}
\hline & $\begin{array}{l}1975 \text { A. Oras, l'Énéide en } \\
\text { estonien } \\
1982 \text { E. Etkind, Un art en } \\
\text { crise. Pour une poétique de la } \\
\text { traduction poétique }\end{array}$ & \\
\hline & $\begin{array}{l}1985 \text { A. Markowicz traduit } \\
\text { Catulle en français }\end{array}$ & \\
\hline $\begin{array}{l}1990 \text { S. G. Daitz enregistre } \\
\text { L'Iliade en grec ancien }\end{array}$ & & $\begin{array}{l}1991 \text { Fr. Mugler, L’Odyssée } \\
\text { en vers de } 14 \text { syllabes } \\
1993 \text { J. Kany-Turpin, } \\
\text { Lucrèce en vers libres }\end{array}$ \\
\hline $\begin{array}{l}1995 \text { A. García Calvo, } \\
\text { L'Iliade en espagnol } \\
1995 \text { Premier spectacle } \\
\text { du Théâtre Démodocos, } \\
\text { Le Retour d'Ulysse, trad. } \\
\text { Ph. Brunet, mise en scène R. } \\
\text { Ayres }\end{array}$ & $\begin{array}{l}1997 \text { Le costellazioni. Esametri } \\
\text { de T. Scialoja } \\
1997 \text { A. García Calvo, } \\
\text { Lucrecio. De rerum natura / } \\
\text { De la Realidad }\end{array}$ & 1995 Fr. Mugler, L'Iliade \\
\hline $\begin{array}{l}1997 \text { D. Sluşanschi, L'Odyssée } \\
\text { en roumain } \\
1998 \text { L'Iliade en roumain } \\
1998 \text { S. G. Daitz enregistre } \\
\text { L'Odyssée en grec ancien }\end{array}$ & $\begin{array}{l}\text { 1998-2012 Catulle / } \\
\text { A. Markowicz, Pleurs } \\
\text { d'Ariane, mise en scène } \\
\text { Ph. Brunet } \\
1998 \text { Ph. Brunet traduit la } \\
\text { Batrachomyomachie } \\
1999 \text { les poèmes d'Hésiode }\end{array}$ & \\
\hline $\begin{array}{l}1999 \text { Circé, traduction et mise } \\
\text { en scène de Ph. Brunet }\end{array}$ & 2000 D. Sluşanschi, L'Énéide & \\
\hline $\begin{array}{l}2002 \text { R. Merrill, L'Odyssée, en } \\
\text { anglais } \\
2005 \text { publication orale de } \\
\text { L'Iliade, trad. Ph. Brunet, } \\
\text { lectures intégrales en } \\
\text { Sorbonne, sur rouleaux } \\
\text { au festival d'Avignon ; en } \\
2006 \text { à Athènes sur rouleaux } \\
\text { bilingues }\end{array}$ & & \\
\hline $\begin{array}{l}2007 \text { R. Merrill, L'Iliade, en } \\
\text { anglais }\end{array}$ & & \\
\hline
\end{tabular}




\begin{tabular}{|l|l|l|}
\hline $\begin{array}{l}\text { 2009 début de l'interprétation } \\
\text { d'Homère sur la lyre éthio- } \\
\text { pienne, par Ph. Brunet } \\
\text { 2010 D. Ventre, L'liade, en } \\
\text { italien } \\
2010 \text { Ph. Brunet, L'Iliade, } \\
\text { publication écrite en français }\end{array}$ & \\
\hline & $\begin{array}{l}\text { 2012 R. Merrill, The } \\
\text { Argonautika, Apollonios } \\
\text { Rhodios }\end{array}$ & $\begin{array}{l}\text { 2013 J.-L. Backès, L'Iliade, } \\
\text { vers libre, en français }\end{array}$ \\
\hline $\begin{array}{l}\text { 2014 D. Ventre, L'Odyssée, en } \\
\text { italien }\end{array}$ & & \\
\hline
\end{tabular}

